ARTICLE

\title{
Low dimensional nanostructures of fast ion conducting lithium nitride
}

\author{
Nuria Tapia-Ruiz (10 1,7,8, Alexandra G. Gordon ${ }^{2,8}$, Catherine M. Jewell', Hannah K. Edwards ${ }^{2,3}$, \\ Charles W. Dunnill (1) ${ }^{1}$, James M. Blackman ${ }^{4}$, Colin P. Snape (1) ${ }^{4}$, Paul D. Brown ${ }^{3}$, Ian MacLaren (1) ${ }^{5}$, \\ Matteo Baldoni (i] ${ }^{2,6}$, Elena Besley (10 ${ }^{2}$, Jeremy J. Titman (1) ${ }^{2} \&$ Duncan H. Gregory (i] ${ }^{1 \times}$
}

As the only stable binary compound formed between an alkali metal and nitrogen, lithium nitride possesses remarkable properties and is a model material for energy applications involving the transport of lithium ions. Following a materials design principle drawn from broad structural analogies to hexagonal graphene and boron nitride, we demonstrate that such low dimensional structures can also be formed from an s-block element and nitrogen. Both one- and two-dimensional nanostructures of lithium nitride, $\mathrm{Li}_{3} \mathrm{~N}$, can be grown despite the absence of an equivalent van der Waals gap. Lithium-ion diffusion is enhanced compared to the bulk compound, yielding materials with exceptional ionic mobility. $\mathrm{Li}_{3} \mathrm{~N}$ demonstrates the conceptual assembly of ionic inorganic nanostructures from monolayers without the requirement of a van der Waals gap. Computational studies reveal an electronic structure mediated by the number of Li-N layers, with a transition from a bulk narrow-bandgap semiconductor to a metal at the nanoscale.

\footnotetext{
${ }^{1}$ WestCHEM, School of Chemistry, University of Glasgow, Glasgow G12 8QQ, UK. ${ }^{2}$ School of Chemistry, University of Nottingham, University Park, Nottingham NG7 2RD, UK. ${ }^{3}$ Department of Mechanical, Materials and Manufacturing Engineering, University of Nottingham, University Park, Nottingham NG7 2RD, UK. ${ }^{4}$ Department of Chemical and Environmental Engineering, University of Nottingham, University Park, Nottingham NG7 2RD, UK. ${ }^{5}$ School of Physics and Astronomy, University of Glasgow, Glasgow G12 8QQ, UK. ${ }^{6}$ Istituto per lo Studio dei Materiali Nanostrutturati (ISMN), Consiglio Nazionale delle Ricerche (CNR), Via P. Gobetti 101, 40129 Bologna, Italy. ${ }^{7}$ Present address: Department of Chemistry, Lancaster University, Lancaster LA1 4YB, UK. ${ }^{8}$ These authors contributed equally: Nuria Tapia-Ruiz, Alexandra G. Gordon. ${ }^{凶}$ email: Duncan.Gregory@glasgow.ac.uk
} 
ithium nitride, $\mathrm{Li}_{3} \mathrm{~N}$, was originally proposed for use as an electrolyte in all solid-state $\mathrm{Li}^{+}$ion batteries given its exceptional ionic conductivity at room temperature (ca. $\left.10^{-3} \mathrm{~S} \mathrm{~cm}^{-1}\right)^{1}$. Indeed, for several decades it remained the highest conducting crystalline $\mathrm{Li}^{+}$ion conductor at ambient conditions hampered chiefly by its low decomposition potential despite many ongoing attempts to stabilise it. Doping with late transition metals, however, triggers electronic conductivity that can be exploited in anodes with more than twice the charging capacity of graphite ${ }^{2} \cdot \mathrm{Li}_{3} \mathrm{~N}$ has also been proposed for a myriad of other applications, e.g. as a means of converting $\mathrm{CO}_{2}$ into useful products $^{3}$, as the electron injection layer in organic light-emitting diodes $^{4}$ and as an unusual reducing agent in preparative organic and organometallic chemistry ${ }^{5}$. Further, in $2002 \mathrm{Li}_{3} \mathrm{~N}$ was revealed as a potential candidate for solid-state hydrogen storage given its capability to accommodate up to $10.4 \mathrm{wt} . \% \mathrm{H}_{2}{ }^{6}$. Slow kinetics for $\mathrm{H}_{2}$ sorption and high (de)hydrogenation temperatures are the primary hurdles to overcome before the $\mathrm{Li}-\mathrm{N}-\mathrm{H}$ system can be exploited commercially, however. By combining experiment and calculation, we demonstrate how the changes in electronic structure and reduction of diffusion lengths brought about by chemically nanostructuring $\mathrm{Li}_{3} \mathrm{~N}$ can lead to dramatic changes in electronic properties and ionic transport behaviour.

\section{Results}

Synthesis and characterisation. $\mathrm{Li}_{3} \mathrm{~N}$ nanocrystals grow following the heating and cooling of the bulk nitride powder under a reduced pressure of nitrogen (see "Methods"). Powder X-ray diffraction (PXD) data for the fine powder product matches to hexagonal $\alpha-\mathrm{Li}_{3} \mathrm{~N}(P 6 / \mathrm{mmm} ; a=3.656(2) \AA ; \quad c=3.868(4) \AA)$ (Supplementary Fig. 1). In the nanofibre syntheses, long structures with diameters ranging from $200 \mathrm{~nm}$ to $2 \mu \mathrm{m}$ and lengths in excess of $10 \mu \mathrm{m}$ were produced (Fig. 1). Atomic force microscopic (AFM) measurements confirmed these ranges of thicknesses in the different fibres observed (Supplementary Fig. 2). The morphology of the nanostructured material can be tailored by controlling the preparative conditions to yield different types of nanofibres (see "Methods").

The growth of the one-dimensional (1D) nanostructures can be rationalised in terms of a self-assisted vapour-liquid-solid (VLS) mechanism. Under vacuum, $\mathrm{Li}_{3} \mathrm{~N}$ will decompose at a temperature below the ambient pressure decomposition temperature $\left(815^{\circ} \mathrm{C}\right.$; $\left.\Delta H_{(298 \mathrm{~K})}=-171.3+/-7.7 \mathrm{~kJ} \mathrm{~mol}^{-1}\right)^{7,8}$ (Eq. 1), forming droplets of liquid $\mathrm{Li}$, since the melting point of $\mathrm{Li}\left(T=180.5^{\circ} \mathrm{C}\right)$ lies well below the applied reaction temperatures. These Li seeds would act as nucleation sites for the $\mathrm{N}_{2(\mathrm{~g})}$ species, which supersaturate the $\mathrm{Li}$ droplets and eventually lead to anisotropic growth and $\mathrm{Li}_{3} \mathrm{~N}$ fibre formation. Energy-dispersive X-ray spectroscopy (EDX) data of the fibrous material did not show any traces of other metals such as $\mathrm{Fe}$ (from the wire used to support the reaction vessel), ruling out the possibility of Fe acting as a catalyst or seed for the formation of the fibres described here (Supplementary Fig. 3). Self-catalytic growth of
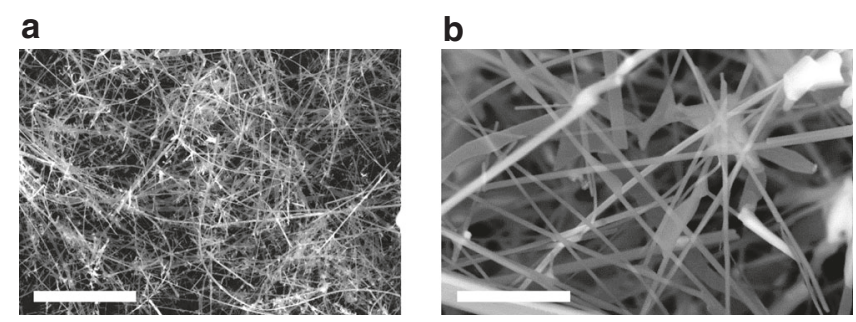

Fig. 1 SEM micrographs of typical $\mathrm{Li}_{3} \mathrm{~N}$ nanofibres (type I) at different magnifications. Images are taken at: $\mathbf{a} \times 500$ and $\mathbf{b} \times 5000$. Scale bars correspond to $50 \mu \mathrm{m}$ (a) and $5 \mu \mathrm{m}$ (b).
GaN nanowires from Ga droplets and gallium/nitrogen vapour species has been observed previously ${ }^{9}$. The comparison to $\mathrm{GaN}$ is apposite in that both binary nitrides are formed from low melting point metals.

$$
2 \mathrm{Li}_{3} \mathrm{~N}_{(\mathrm{s})} \rightarrow 6 \mathrm{Li}_{(\mathrm{l})}+\mathrm{N}_{2(\mathrm{~g})}
$$

Two types of single-crystalline straight fibres with different growth orientations (I and II) form under varying reaction conditions (see Supplementary Tables 1 and 2): type I nanofibres (Fig. 2a, b) exhibit a growth direction of $\langle 10 \overline{1} 0\rangle$, whereas, conversely, type II nanofibres exhibit a growth direction of $<0001>$ (Fig. 2c, d). Typically, type II nanofibres were found together with a few fibres and nanosheets with zig-zag morphology (Supplementary Figs. 4 and 5). Thus $\mathrm{Li}_{3} \mathrm{~N}$ nanofibres exist in which the hexagonal $\left[\mathrm{Li}_{2} \mathrm{~N}\right]$ layers are stacked either parallel or perpendicular to the principal fibre axis. Carbon nanofibres can assemble in an analogous fashion, where graphene layers can be oriented either perpendicular or parallel to the principal fibre axis ${ }^{10,11}$. Our experimental evidence shows that the pressure within the reaction vessel is likely to be the crucial parameter for the preferential growth of type I and II nanofibres, i.e. under identical reaction times and temperature, type II fibres will be favoured over type I fibres at higher reaction pressures (Supplementary Tables 1 and 2). There are several examples in the literature that describe how the total pressure and/or precursor partial pressure can control the growth direction of fibres; these preferences can be both thermodynamically and kinetically driven ${ }^{12}$. Indeed, in this respect, our density functional theory (DFT) calculations suggest that type I nanofibres $\left(-325.44 \mathrm{eV} \mathrm{Li}_{3} \mathrm{~N}\right.$ unit ${ }^{-1}$ see "Methods") are more thermodynamically stable than the equivalent type II fibres $\left(-324.59 \mathrm{eV} \mathrm{Li} \mathrm{L}_{3} \mathrm{~N}\right.$ unit $\left.^{-1}\right)$. The dependence of growth direction on seed concentration in layered $\mathrm{BN}$ and $\mathrm{GaN}$ fibres has been previously reported ${ }^{13,14}$. Moreover, it has been well documented that nanowire growth direction is directly impacted by pressure across diverse systems of varying complexity (e.g. in semiconductors such as $\mathrm{Si}, \mathrm{In}_{2} \mathrm{O}_{3}$ and $\left.\mathrm{InN}\right)^{15-18}$. One might expect an increased $\mathrm{Li}$ seed concentration at elevated reaction pressure. An increase in $\mathrm{N}_{2}$ partial pressure (concentration) and the $\mathrm{N}: \mathrm{Li}$ ratio at the growth interface should lead to the formation of Li-N planes and type II fibre propagation. Local variation in pressure and $\mathrm{N}: \mathrm{Li}$ stoichiometry might, therefore, account for the formation of zig-zag (kinked) nanofibres and sheets observed in type II samples (Supplementary Figs. 4 and 5); analogous behaviour has been noted for $\mathrm{Si}$ and $\mathrm{InN}$ nanowires, for example ${ }^{16,17}$.

Raman spectra from nanostructured $\mathrm{Li}_{3} \mathrm{~N}$ (fibres type I and type II) and bulk $\mathrm{Li}_{3} \mathrm{~N}$ showed one prominent peak at ca. $580 \mathrm{~cm}^{-1}$, attributable to the only Raman active mode of $\mathrm{Li}_{3} \mathrm{~N}$, i.e. $E_{2 \mathrm{~g}}$ (Supplementary Fig. 6). This phonon mode corresponds to the displacement of the $\mathrm{Li}(2)$ and $\mathrm{N}$ atoms along the $a b$ plane in $\mathrm{Li}_{3} \mathrm{~N}^{19}$ and is consistent with group theory predictions and the spectra of bulk $\mathrm{Li}_{3} \mathrm{~N}^{20}$. We found that the $E_{2 \mathrm{~g}}$ mode band was slightly blue-shifted (by ca. $5 \mathrm{~cm}^{-1}$ ) with respect to the bulk for both type I and type II fibres. Raman spectra of microcrystals of structurally similar graphite and $\mathrm{BN}^{21,22}$ and of $\mathrm{BN}$ nanotubes ${ }^{23}$ also revealed that the $E_{2 \mathrm{~g}}$ band broadens and shifts to a higher frequency as particle size decreases. Ab-initio calculations on $\mathrm{BN}$ single-walled nanotubes attribute the blue shift in the $E_{2 \mathrm{~g}}$ mode (of $5 \mathrm{~cm}^{-1}$ ) to a shortening of the $\mathrm{sp}^{2}$ bonds with respect to the bulk 23 . The additional bands observed at ca. $500 \mathrm{~cm}^{-1}$ and $650 \mathrm{~cm}^{-1}$ in both bulk and nanoscale $\mathrm{Li}_{3} \mathrm{~N}$ samples were assigned to the acoustic (A) and optical phonon (O) modes 2 TA (z, K), 2 TO(A) and $2 \mathrm{LA}(\mathrm{A})(\mathrm{T}=$ transverse, $\mathrm{L}=$ longitudinal $)$ by direct comparison with the second-order Raman spectra of $\mathrm{Li}_{3} \mathrm{~N}^{19,24}$. Bands corresponding to the second-order phonon mode (2 LA $(\mathrm{M}, \mathrm{K})$ ) 
a

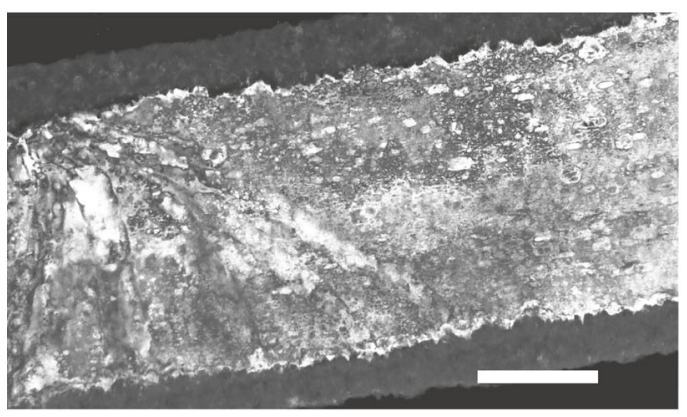

C

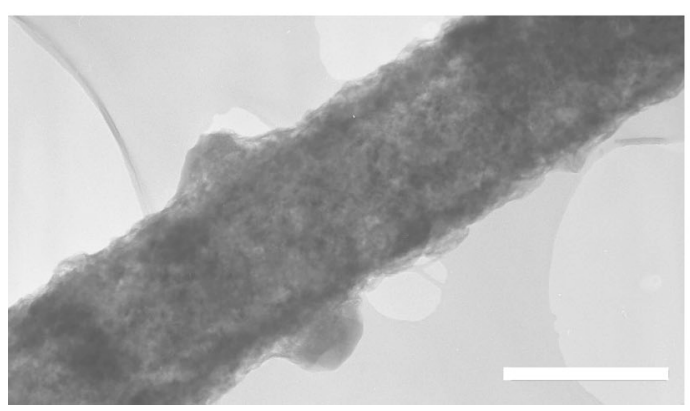

b

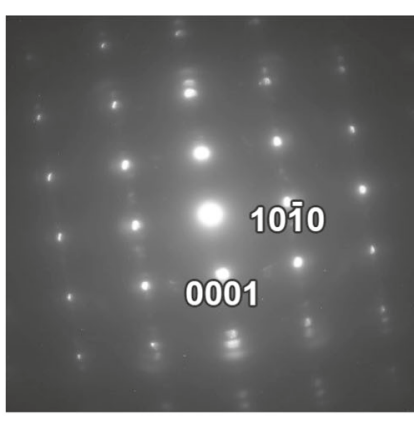

d

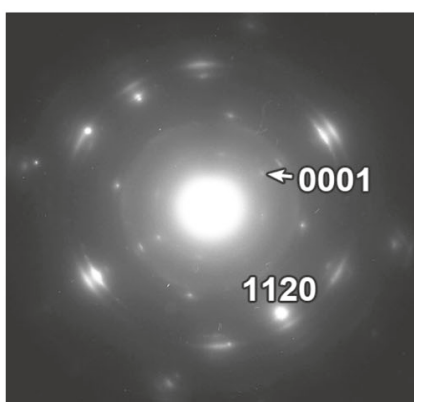

Fig. 2 Transmission electron microscopic (TEM) images and selected area electron diffraction (SAED) patterns of type I and type II fibres. a Highmagnification dark-field TEM image of a type I fibre ( $\mathrm{Li}_{3} \mathrm{~N}$ core and an $\mathrm{LiOH}$ outer layer) and $\mathbf{b}$ corresponding SAED pattern in the $<\overline{1} 2 \overline{1} 0>$ projection demonstrating the $<10 \overline{1} 0>$ nanofibre growth direction; c bright-field TEM image of a type II fibre and $\mathbf{d}$ corresponding SAED pattern in the $<01 \overline{1} 0>$ projection (with arcs due to an $\mathrm{LiOH}$ surface layer) showing the $<0001>$ growth direction. Scale bars in a and $\mathbf{c}$ correspond to $500 \mathrm{~nm}$.

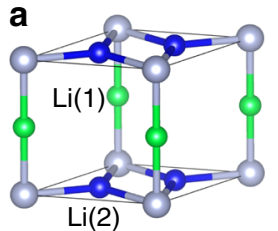

b

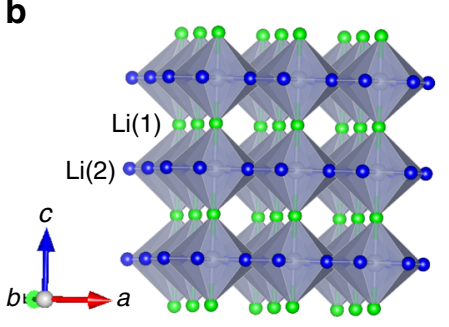

d

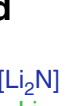

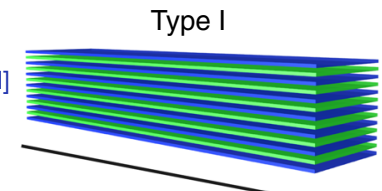

Long axis of the fibre
C

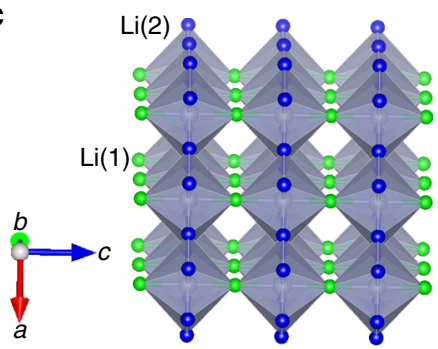

e

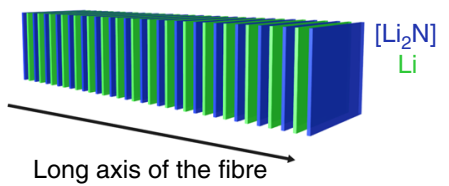

Fig. 3 Schematic diagrams illustrating the $\mathrm{Li}_{\mathbf{3}} \mathbf{N}$ crystal structure and type $\mathbf{I}$ and type II nanofibres. a $\mathrm{Li}_{3} \mathrm{~N}$ unit cell, showing Li(1) atoms (green spheres), $\mathrm{Li}(2)$ atoms (blue spheres) and $\mathrm{N}$ (grey spheres); polyhedral representations of $\mathrm{Li}_{3} \mathrm{~N}$ showing $\mathrm{Li}(1)$ atoms and $\mathrm{Li}(2)$ atoms: $\mathbf{b}$ aligned in the $a b$ direction and c perpendicular to the $a b$ direction; corresponding depictions of $\mathbf{d}$ type I and $\mathbf{e}$ type $\mathrm{II} \mathrm{Li}_{3} \mathrm{~N}$ nanofibres, based on the orientation of the $\mathrm{Li}$ (green) and [Li $\mathrm{N}^{\mathrm{N}}$ layers (blue) with respect to the long axis of the fibre.

were also observed in the $250-460 \mathrm{~cm}^{-1}$ region. The presence of these modes is attributed to the resonant conditions established when using laser irradiation, i.e. at $2.33 \mathrm{eV}^{25}$.

The layered crystal structure of $\mathrm{Li}_{3} \mathrm{~N}$ (hexagonal $P 6 / \mathrm{mmm}$ ) shares salient symmetry features with those of hexagonal graphite and $\mathrm{BN}$. $\left[\mathrm{Li}_{2} \mathrm{~N}\right]$ layers contain $\mathrm{Li}$ atoms in trigonal planar coordination to $\mathrm{N}$, ostensibly by analogy to $\mathrm{sp}^{2}$ hybridised carbon in the graphene layers of graphite or to boron and nitrogen in $\mathrm{BN}$ (Fig. 3$)^{1}$. Given the formation of anisotropic fibres (types I and II; Fig. 3) like layered chalcogenides, $\mathrm{MX}_{2}(\mathrm{M}=$ early transition metal; $\mathrm{X}=\mathrm{S}, \mathrm{Se}$ ), it may be tempting to classify $\mathrm{Li}_{3} \mathrm{~N}$ as an extension of this latter class of materials ${ }^{26}$. Importantly, however, what distinguishes $\mathrm{Li}_{3} \mathrm{~N}$ from the above examples is the absence of a van der Waals gap; although anisotropic, $\mathrm{Li}_{3} \mathrm{~N}$ is connected in the third dimension by $\mathrm{Li}$ atoms (forming infinite [-Li-N-Li-] chains).

$\mathrm{Li}^{+}$and $\mathrm{H}^{+}$transport properties. Given the exceptional $\mathrm{Li}^{+}$fast ionic conducting properties of bulk $\mathrm{Li}_{3} \mathrm{~N}$, we wished to understand how the ionic transport might vary as a consequence of 
a

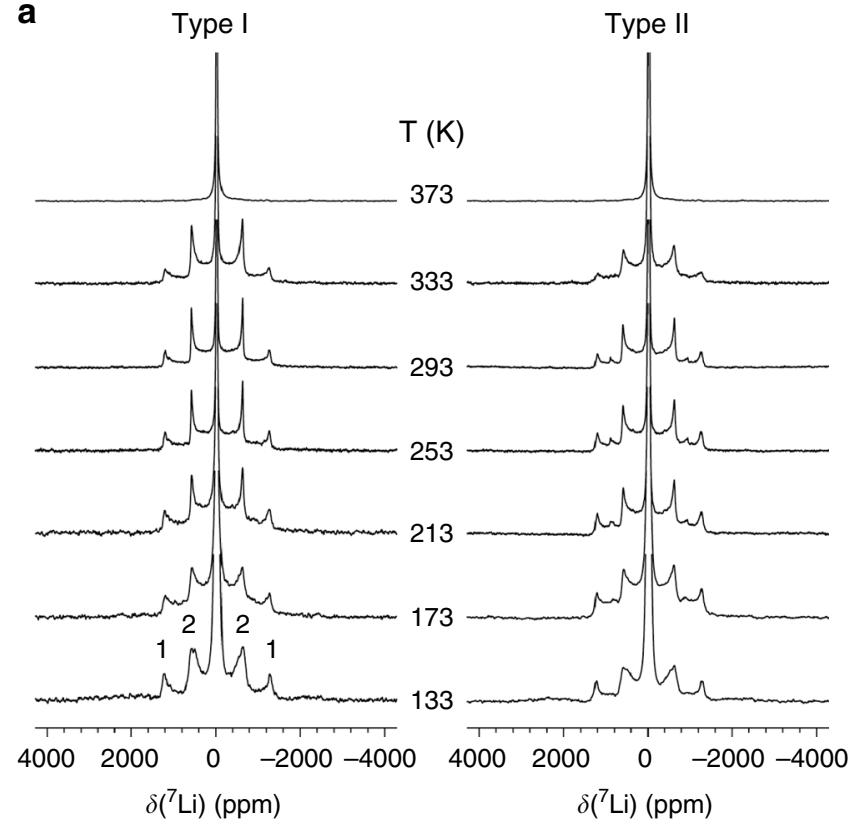

b

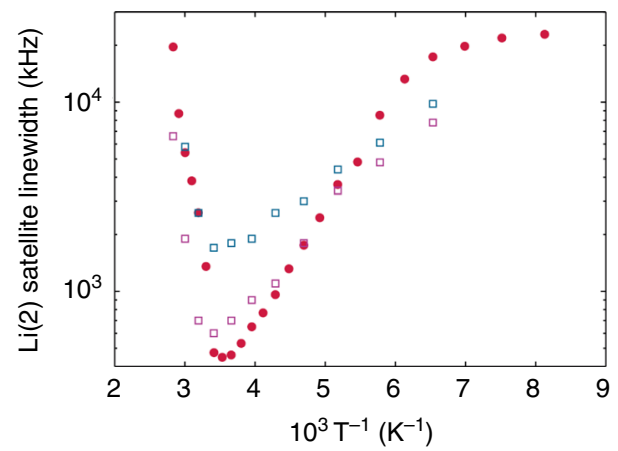

Fig. $4{ }^{7} \mathrm{Li}$ NMR characterisation at variable temperatures of type I and II fibres. a Variable-temperature (VT) wideline ${ }^{7} \mathrm{Li}$ NMR spectra recorded between 133 and $373 \mathrm{~K}$ for type I (left) and type II (right) $\mathrm{Li}_{3} \mathrm{~N}$ nanofibres. 1 and 2 denote satellite bands for the two-coordinate $\mathrm{Li}(1)$ site and threecoordinate $\mathrm{Li}(2)$ site, respectively; $\mathbf{b}$ temperature variation of the linewidth of the Li(2) satellites for type I (magenta) and II (blue) $\mathrm{Li}_{3} \mathrm{~N}$ nanofibres and bulk $\mathrm{Li}_{3} \mathrm{~N}$ (red) ${ }^{28}$ extracted from the VT NMR by fitting a simulated powder lineshape.

nanostructuring. Variable-temperature wideline ${ }^{7} \mathrm{Li}$ solid-state nuclear magnetic resonance (NMR) measurements between 133 and $373 \mathrm{~K}$ enabled the local structure of the type I and type II nanofibres to be probed and allowed the $\mathrm{Li}^{+}$ion transport properties of the $\mathrm{Li}_{3} \mathrm{~N}$ nanofibres to be determined (Fig. 4, Supplementary Note 2 and Supplementary Figs. 7 and 8). The line narrowing observed particularly for the $\operatorname{Li}(2)$ satellite lines between 133 and $293 \mathrm{~K}$ can be interpreted in terms of intra-layer $\mathrm{Li}^{+}$diffusion, by analogy with the corresponding behaviour for bulk $\mathrm{Li}_{3} \mathrm{~N}^{27}$. Similarly, the broadening that occurs $>293 \mathrm{~K}$ and eventually causes both sets of satellites to disappear into the baseline results from inter-layer diffusion via an exchange of $\mathrm{Li}^{+}$between the $\mathrm{Li}(1)$ and $\mathrm{Li}(2)$ sites. Assuming simple Arrhenius behaviour, the activation energy for the former intralayer process can be measured from the temperature variation of the linewidth and was found to be 0.075 and $0.053 \mathrm{eV}$ for type I and II $\mathrm{Li}_{3} \mathrm{~N}$ nanofibres, respectively, which should be compared with the value of $0.121 \mathrm{eV}$, previously obtained for bulk $\mathrm{Li}_{3} \mathrm{~N}^{28}$ (Supplementary Table 3). Hence, $\mathrm{Li}^{+}$ion hopping becomes more facile within the Li-N planes as a result of nanofibre formation. Electrochemical impedance spectroscopic measurements were attempted on these samples to corroborate the conductivity results obtained by NMR. However, the high temperatures required to sinter pellets pressed from the $\mathrm{Li}_{3} \mathrm{~N}$ nanofibres (i.e. to reduce grain boundary resistances) compromised their nanostructured morphology, so although high values of conductivity could be obtained (ca. $1 \times 10^{-3} \mathrm{~S} \mathrm{~cm}^{-1}$ ), we could not treat the data obtained as representative of the fibres.

High $\mathrm{Li}^{+}$ion conductivity is a fundamental requirement for solid electrolytes to compete against organic electrolytes in lithium-ion batteries. To date, only a few sulfide-type electrolytes have shown comparable ionic conductivities to commercial organic electrolytes ${ }^{29}$. Thus nanostructuring of solid electrolytes might be a plausible approach to increase ionic conductivity. This field is only at its infancy, with most of the work conducted on the $\mathrm{Li}_{7} \mathrm{La}_{3} \mathrm{Zr}_{2} \mathrm{O}_{12}$ garnet solid electrolyte (as a sintered ceramic or as an inorganic filler component in solid composite polymer electrolytes) ${ }^{30}$. Nevertheless, given the low decomposition potential of $\mathrm{Li}_{3} \mathrm{~N}$ (ca. $0.45 \mathrm{~V}$ vs. $\left.\mathrm{Li}^{+} / \mathrm{Li}\right)^{31}$ and the enhanced electronic conductivity expected in these nanostructured materials when compared to the bulk (see "DFT calculations" section), the use of $\mathrm{Li}_{3} \mathrm{~N}$ as a solid electrolyte seems implausible from a practical point of view. On the other hand, in lithium-containing hydrogen storage materials, e.g. the lithium amide-lithium imide system, proton mobility has been intrinsically linked to $\mathrm{Li}^{+}$ion diffusion ${ }^{32}$. Hence, we expected that the high $\mathrm{Li}^{+}$ion mobility observed in these $\mathrm{Li}_{3} \mathrm{~N}$ nanofibres may lead to improved hydrogen absorption properties.

Preliminary volumetric experiments to determine the hydrogen uptake properties of the nanostructured $\mathrm{Li}_{3} \mathrm{~N}$ material were conducted by differential pressure analysis (DPA). As compared to bulk samples of highly crystalline, single-phase $\mathrm{Li}_{3} \mathrm{~N}$, the initial $\mathrm{H}_{2}$ uptake for the nano- $\mathrm{Li}_{3} \mathrm{~N}$ material was found to be lower $(8.9$ vs. $10.5 \mathrm{wt} \%)$. The latter uptake is typical for pristine bulk material and matches the theoretical capacity from a two-step reaction mechanism (Eq. 2)

$$
\mathrm{Li}_{3} \mathrm{~N}+2 \mathrm{H}_{2} \leftrightarrow \mathrm{Li}_{2} \mathrm{NH}+\mathrm{LiH}+\mathrm{H}_{2} \leftrightarrow \mathrm{LiNH}_{2}+2 \mathrm{LiH}
$$

One might postulate that the reduction in initial gravimetric capacity in the nanofibres is a result of surface hydrolysis (passivation) on handling in air (as observed from transmission electron microscopy (TEM)/selected area electron diffraction experiments; Supplementary Note 1 and Supplementary Fig. 9). Nevertheless, there is a greater than threefold increase in the rate of hydrogen sorption for nanocrystalline $\mathrm{Li}_{3} \mathrm{~N}$ with respect to the bulk material in the first cycle, which dramatically improves further in subsequent uptake cycles (Supplementary Fig. 10). The microstructure of the dehydrogenated nitride is retained through cycling (from imide to amide and vice versa) and hence the (de) hydrogenation process is pseudomorphic and reversible (Supplementary Fig. 11). The enhanced hydrogen uptake behaviour of the nanofibres is broadly analogous to the uptake kinetics observed when $\mathrm{Li}_{3} \mathrm{~N}$ is impregnated in mesoporous carbon or used in carbon nanocomposites (also at a reduced sorption temperature of $200^{\circ} \mathrm{C}$ and which exhibit a hydrogen desorption enthalpy that is half that of the bulk material) ${ }^{33}$. Unlike these composites, however, the nanofibres do not suffer from the gravimetric capacity penalty imposed by an inactive component. Computational studies have demonstrated that pseudo-molecular $\left(\mathrm{Li}_{3} \mathrm{~N}\right)_{n} \quad(n=1-7)$ clusters would bind $\mathrm{H}_{2}$ via coordinatively unsaturated $\mathrm{Li}$ atoms with an adsorption energy approximately an order of magnitude smaller than that of the bulk material ${ }^{34}$. By extension, earlier DFT calculations show that the most favourable adsorption sites for both $\mathrm{H}_{2}$ and dissociated $\mathrm{H}$ atoms are to $\mathrm{N}$ positions on the (001) surface of $\mathrm{Li}_{3} \mathrm{~N}^{35}$. Semi-quantitatively at 
a

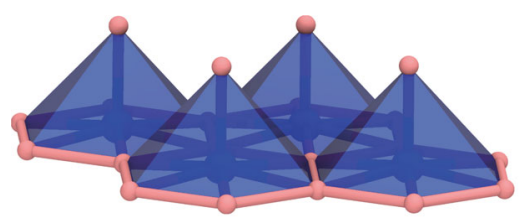

Monolayer 1

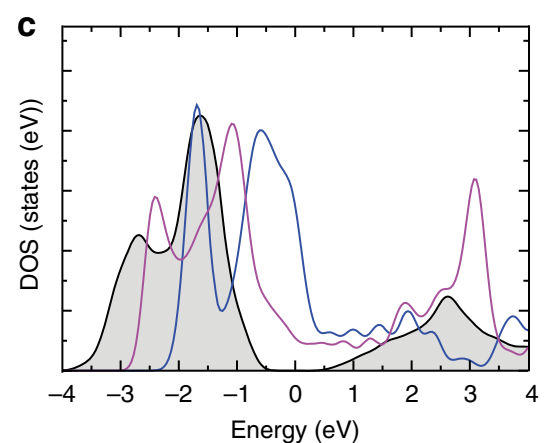

b

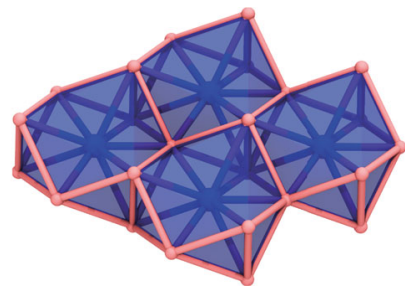

Monolayer 2

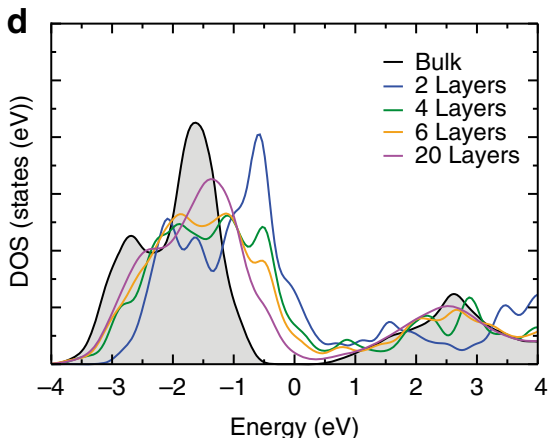

Fig. $5 \mathrm{Li}_{3} \mathbf{N}$ monolayer configurations and electronic structures determined from density functional theory calculations. Calculated $\mathrm{Li}_{3} \mathrm{~N}$ monolayer structures of: a form 1; b form 2; c comparison of the total DOS for bulk $\mathrm{Li}_{3} \mathrm{~N}$ (black) with form 1 (blue) and 2 (magenta) monolayers, respectively; d evolution of the total DOS for increasing numbers of $\mathrm{Li}_{3} \mathrm{~N}$ layers (2 (blue), 4 (green), 6 (yellow) and 20 (magenta)) as compared to that of the bulk material (black).

least, both prior studies would indicate that fabrication of narrow nanofibres or thin nanosheets of $\mathrm{Li}_{3} \mathrm{~N}$ should produce storage materials with improved sorption kinetics. Thus the design and optimisation of anisotropic $\mathrm{Li}-\mathrm{N}(-\mathrm{H})$ nanomaterials could prove a useful strategy towards attaining a storage solution that meets the challenging criteria required for implementing hydrogen as a fuel for transport. Further studies should establish whether this is indeed the case.

Calculations on nanostructured $\alpha-\mathrm{Li}_{3} \mathrm{~N}$ electronic properties. Electronic properties were computed on $\alpha-\mathrm{Li}_{3} \mathrm{~N}$ using DFT to compare the behaviour of a monolayer of $\mathrm{Li}_{3} \mathrm{~N}$ with respect to the bulk material and to develop an understanding of the evolution of electronic structure with the number of layers as compared to graphene and other van der Waals nanostructures (vdWNs). Our calculations confirm that bulk $\alpha-\mathrm{Li}_{3} \mathrm{~N}$ is a semiconductor with an indirect bandgap of $E_{\mathrm{g}}=1.3 \mathrm{eV}$, in agreement with several previous first-principles calculations of the $\alpha-\mathrm{Li}_{3} \mathrm{~N}$ electronic properties $^{36-39}$. The electronic bandgap predicted by DFT is notably smaller than the experimental optical bandgap of $2.18 \mathrm{eV}$ for $\mathrm{Li}_{3} \mathrm{~N}$ single crystals ${ }^{40}$. This discrepancy is due to the well-known DFT problem in underestimating conduction band state energies ${ }^{41,42}$. Unlike layers in vdWNs, a single $\left[\mathrm{Li}_{2} \mathrm{~N}\right]$ layer is unstable and computational optimisation produces two monolayer structures from the combination of $\left[\mathrm{Li}_{2} \mathrm{~N}\right]$ and $[\mathrm{Li}]$ planes, forms 1 and 2 (Fig. $5 \mathrm{a}, \mathrm{b}$ ), of which the latter is more stable by $-0.574 \mathrm{eV}$.

Although the profile of the single-layer density of states (DOS) more closely resembles that of the bulk material for the form 2 monolayer, both single-layer forms are predicted to be metallic (Fig. 5c). In each case, the DOS below and approaching the Fermi level is attributable to $\mathrm{N}$ states, whereas the higher states of the conduction band are composed predominantly of $\mathrm{Li}$ states. As the number of layers in a $\mathrm{Li}_{3} \mathrm{~N}$ slab is increased, the total DOS at the Fermi level decreases and a clear tendency towards an opening of a bandgap is observed (Fig. $5 \mathrm{~d}$ ). $\mathrm{Li}_{3} \mathrm{~N}$ nanosheets composed of up to 20 layers ( $75.6 \AA$ thick), for example, remain metallic, although using accurate quantum chemical approaches it is difficult to predict a critical thickness at which the metal-semiconductor transition occurs. The evolution of the electronic structure contrasts markedly with graphene, where there is a relatively abrupt change from zero bandgap semiconducting to semi-metallic graphite-like behaviour as the number of stacked monolayers increases ${ }^{43}$. Experimental data suggest that the bandgap in $\mathrm{BN}$ 5-layer nanosheets $(5.56 \mathrm{eV})$ is smaller than that calculated for a $\mathrm{BN}$ monolayer $(6 \mathrm{eV})$, but both values are larger than that of the bulk material (5.2-5.4 eV) and the nitride remains an insulator ${ }^{44-46}$.

\section{Discussion}

In summary, anisotropic $1 \mathrm{D} \mathrm{Li}_{3} \mathrm{~N}$ nanostructured materials can be formed by broad analogy to $\mathrm{sp}^{2}$-like layered solids such as graphite and boron nitride, despite the absence of a van der Waals gap in $\mathrm{Li}_{3} \mathrm{~N}$. Two distinct types of $\mathrm{Li}_{3} \mathrm{~N}$ fibres have been identified, here denoted as type I and type II, which differ in the orientation of the $\left[\mathrm{Li}_{2} \mathrm{~N}\right]$ layers (parallel or perpendicular) with respect to the long axis of the fibre. The formation of $1 \mathrm{D}$ structural variants of $\mathrm{Li}_{3} \mathrm{~N}$ has important consequences for the transport of $\mathrm{Li}^{+}$(and $\mathrm{H}^{+}$) ions, which lead to demonstrable differences in diffusion behaviour compared to the bulk material. DFT calculations have shown that the electronic properties of these $\mathrm{Li}_{3} \mathrm{~N}$ materials appear scalable with size and shape.

Given their predicted metallic-like behaviour and high $\mathrm{Li}^{+}$ion mobility, we anticipate that these nano-based $\mathrm{Li}_{3} \mathrm{~N}$ materials could play an important role as additives in high-power Li-based batteries, which demand rapid ionic and electronic kinetics. Currently, bulk and surface-passivated $\mathrm{Li}_{3} \mathrm{~N}$ has been used as a pre-lithiation additive in various cathode materials (e.g. LCO, NMC) $)^{47,48}$ to offset the first-cycle lithium loss and thus to improve the overall energy density of the material. Furthermore, bulk $\mathrm{Li}_{3} \mathrm{~N}$ has been used as a protective coating for $\mathrm{Li}$ metal anodes in $\mathrm{Li}$-ion and $\mathrm{Li}-\mathrm{S}$ batteries to avoid dendrite growth and parasitic reactions between polysulfides and $\mathrm{Li}$ metal ${ }^{49,50}$. Importantly, the nanostructured materials allow for the rapid growth of an insulating surface passivation layer (e.g. formed from $\mathrm{Li}_{2} \mathrm{CO}_{3}$ ) conferring higher chemical stability that could 
eliminate reactions at the electrolyte interface. From a different perspective, the superior $\mathrm{Li}^{+}$ion diffusion in the $\mathrm{Li}_{3} \mathrm{~N}$ nanofibers leads to improved hydrogen absorption/desorption properties in the $\mathrm{Li}-\mathrm{N}-\mathrm{H}$ system given the intrinsic relationship between proton and lithium-ion conduction in this system. Thus, by analogy, it may be conceivable to revisit other materials related to the $\mathrm{Li}-\mathrm{N}-\mathrm{H}$ family of compounds to explore the impact of nanoscaling on hydrogen storage and generation more widely.

Our studies clearly demonstrate that combining an s-block element with nitrogen under the appropriate synthetic conditions can lead to the formation of anisotropic nanomaterials. Nanostructuring has a palpable influence on many chemical and physical properties in the $\mathrm{Li}-\mathrm{N}$ system and there are likely to be other exciting phenomena and behaviours to be discovered. We expect that this work will stimulate further research on this system and those containing other s-block elements.

\section{Methods}

Synthesis of type I Li ${ }_{3} \mathbf{N}$ nanofibres. $\alpha-\mathrm{Li}_{3} \mathrm{~N}$ (ca. $0.1 \mathrm{~g}$ ) prepared from the nitridation of a sodium/lithium alloy ${ }^{28}$ was contained within an iron foil liner that was placed inside a stainless-steel crucible. The crucible was suspended by an iron wire inside a long, $3 \mathrm{~cm}$ internal diameter stainless-steel reaction vessel that was watercooled at the upper end. The vessel was evacuated to a pressure of ca. $5 \mathrm{~Pa}$ (a range of 4-6.7 Pa), then sealed and heated to $1023-1073 \mathrm{~K}$ in a vertical furnace for 6 days. Finally, the furnace was cooled to room temperature. Supplementary Table 1 provides detailed reaction conditions for each of the syntheses performed that yielded type $\mathrm{I} \mathrm{Li}_{3} \mathrm{~N}$ nanofibres.

Synthesis of type II $\mathbf{L i}_{3} \mathbf{N}$ nanofibres. $\alpha-\mathrm{Li}_{3} \mathrm{~N}$ (ca. $0.1 \mathrm{~g}$ ) prepared from the nitridation of a sodium/lithium alloy ${ }^{28}$ was contained within an iron foil liner that was placed inside a stainless-steel crucible. The crucible was suspended by an iron wire inside a long, $1.5 \mathrm{~cm}$ internal diameter stainless steel reaction vessel that was water-cooled at the upper end. The vessel was evacuated to a pressure of ca. $10 \mathrm{~Pa}$ (a range of 9.3-10.7 Pa), then sealed and heated to 1023-1043 K in a vertical furnace for 6 days. Finally, the furnace was cooled to room temperature. Supplementary Table 2 shows detailed reaction conditions for each of the syntheses

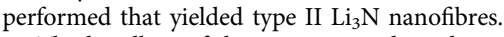

The handling of the reactants and products took place in a nitrogen-filled glovebox (Saffron Scientific Ltd.; $\mathrm{O}_{2}<5 \mathrm{ppm} ; \mathrm{H}_{2} \mathrm{O}<10 \mathrm{ppm}$ ) during the syntheses of both types of nanofibres. In both cases, on cooling, red/dark purple fibrous material $(10-40 \mathrm{mg})$ was found deposited on the Fe wire above the reaction crucible. EDX spectra of all nanomaterials reveal peaks only from nitrogen (and oxygen from brief air exposure). Given that $\mathrm{Li}$ is not detectable by EDX and that no peaks from lithium metal (or other Li-containing phases) are observed in solidstate NMR spectra, the results are consistent with the presence of single-phase $\mathrm{Li}_{3} \mathrm{~N}$. The absence of metal impurity peaks corroborates a self-assisted growth mechanism.

Powder X-ray diffraction. PXD data were collected using a Philips X'Pert $\theta-2 \theta$ diffractometer with a PW3710 control unit using $\mathrm{Cu}$ Ka radiation $(\lambda=1.5418 \AA$ ), operating at $40 \mathrm{kV}$ and $40 \mathrm{~mA}$. Samples were run within a bespoke air-tight aluminium holder with Mylar windows ${ }^{51}$. Data were collected in the range from 5 to $80^{\circ} 2 \theta$ in steps of $0.025^{\circ} \mathrm{s}^{-1}$. Sample preparation for analysis took place in an $\mathrm{N}_{2^{-}}$ filled glovebox. Lattice parameters were refined by least-squares fitting using the CELL software package ${ }^{52}$.

Scanning electron microscopy (SEM). A Philips XL30 ESEM-FEG instrument was used for SEM and EDX characterisation. Experiments were performed in high vacuum mode with an applied accelerating voltage of $15 \mathrm{kV}$. Samples were loaded onto aluminium stubs using adhesive carbon tabs and the transfer was performed under a stream of flowing $\mathrm{N}_{2}$ gas.

Atomic force microscopy. AFM sample preparation consisted of dispersing the samples in n-propyl acetate in an Ar-filled glove box. Then a droplet of the concentrated $\mathrm{Li}_{3} \mathrm{~N}$ solution was placed onto a silicon wafer for measurement. AFM analyses were carried out using a Keysight 5500 instrument in tapping mode to produce topographical information of the samples.

Transmission electron microscopy. TEM analyses were performed using different instruments under varying operating conditions. Measurements performed at $80 \mathrm{kV}$ were conducted using a JEOL JEM-2200MCO FEGTE. Samples were loaded in an $\mathrm{N}_{2}$-filled glovebox onto a custom-made air-tight holder to minimise air exposure during transfer. Analyses performed at $200 \mathrm{kV}$ were made using either a JEOL JEM-2000FX II TEM or an FEI Tecnai $G^{2} 20$ TEM. TEM samples were prepared by depositing the $\mathrm{Li}_{3} \mathrm{~N}$ dry onto a 3-mm holey carbon film copper grid in an $\mathrm{N}_{2}$-filled glovebox. Each grid was placed within a sealed container and transferred to the instrument under a stream of $\mathrm{N}_{2}$. In both cases, a small condenser aperture was used to reduce beam damage (the result of which is evident in Supplementary Fig. 12) and evaporation due to the instability of nanoscale $\mathrm{Li}_{3} \mathrm{~N}$ under the beam.

${ }^{7} \mathrm{Li}$ NMR spectroscopy. Wideline ${ }^{7} \mathrm{Li} \mathrm{NMR}$ spectra of $\mathrm{Li}_{3} \mathrm{~N}$ nanomaterials were recorded from 133 to $453 \mathrm{~K}$ at a Larmor frequency of $116.6 \mathrm{MHz}$ on a Varian InfinityPlus Spectrometer equipped with a single-resonance broadband probe. Spectra were obtained using an EXORCYCLED solid-echo sequence with $\pi / 2$ pulses of $1.3 \mu \mathrm{s}$ and an echo delay of $16.0 \mu$ s. Relaxation delays between 0.5 and $10 \mathrm{~s}$ were used depending on the temperature. Chemical shifts are referenced externally to aqueous $\mathrm{LiCl}$.

Raman spectroscopy. Raman spectra were collected using a Horiba-Yvon LabRam HR spectrometer with a confocal microscope at room temperature using a 532 -nm laser with a $600 \mathrm{~g} \mathrm{~mm}^{-1}$ grating and a Synapse CCD detector. Samples were mounted in sealed glass capillaries in an $\mathrm{N}_{2}$-filled glovebox to avoid air exposure. A ten times reduced incident laser power $(15 \mathrm{~mW})$ was used together with a $100-\mathrm{nm}$ aperture to avoid damaging the material under the beam during analysis.

Hydrogen storage measurements. Volumetric hydrogen uptake measurements were performed by loading ca. $0.2 \mathrm{~g}$ sample into a Swagelock tube in an $\mathrm{N}_{2}$-filled glovebox and sealed using parafilm. The tube was connected to the DPA apparatus $^{53}$ and the parafilm was seal-broken using a flow of helium gas. The sample was evacuated before exposure to hydrogen and heated to the reaction temperature. $\mathrm{H}_{2(\mathrm{~g})}$ and $\mathrm{He}_{(\mathrm{g})}$ were dried using a liquid nitrogen trap before use. Hydrogen uptake was performed at $10 \mathrm{bar}$ at $200^{\circ} \mathrm{C}$. After reaching equilibrium, the sample was desorbed at $200^{\circ} \mathrm{C}$ before performing the next absorption cycle.

DFT calculations. Electronic properties of bulk and nano-sheets of $\alpha-\mathrm{Li}_{3} \mathrm{~N}$ were calculated at the gradient-corrected DFT level by applying the

Perdew-Burke-Ernzerhof ${ }^{54}$ exchange-correlation functional as implemented in the SIESTA program package ${ }^{55}$. Electronic states were expanded by a double- $\zeta$ plus polarisation basis set with norm-conserving Troullier-Martins pseudopotentials ${ }^{56}$ for the description of core levels and a plane-wave representation of the charge density with a cut-off of $240 \mathrm{Ry}$. The reciprocal space was sampled by a Monkhorst-Pack grid ${ }^{57}$ of $16 \times 16 \times 32 k$-points in the Brillouin zone $(16 \times 16 \times 1$ $k$-points in the case of nanosheets). Models of nanosheets are composed of an increasing number of unit cell replicas constructed in the direction perpendicular to the nano-sheet plane and a $15-\AA$-thick vacuum region. Geometries of all systems were relaxed until a maximum gradient of $0.02 \mathrm{eV} \AA^{-1}$ on forces was reached. In the calculations of the total energies of type I and type II nanofibres, the model structures were built with an increasing number of replicas of the unit cell in the non-periodic directions to achieve the convergence in terms of energy per number of replicas (14 replicas were used for type I nanofibre and $8 \times 8$ for type II nanofibre). An MP $k$-points sampling with $16 k$-points in the periodic directions has been applied (two directions for type I nanofibre and one direction for type II nanofibre).

\section{Data availability}

The authors declare that the data supporting the findings of this study are available within the paper and its supplementary information files.

Received: 14 November 2018; Accepted: 28 July 2020; Published online: 08 September 2020

\section{References}

1. Boukamp, B. A. \& Huggins, R. A. Fast ionic conductivity in lithium nitride. Mater. Res. Bull. 13, 23-32 (1978).

2. Shodai, T., Okada, S., Tobishima, S. \& Yamaki, J. Study of $\operatorname{Li}_{3-\mathrm{x}} \mathrm{M}_{\mathrm{x}} \mathrm{N}$ (M: Co, $\mathrm{Ni}$ or $\mathrm{Cu}$ ) system for use as anode material in lithium rechargeable cells. Solid State Ionics 86-88, 785-789 (1996).

3. Hu, Y. H. \& Huo, Y. Fast and exothermic reaction of $\mathrm{CO}_{2}$ and $\mathrm{Li}_{3} \mathrm{~N}$ into C-Ncontaining solid materials. J. Phys. Chem. A 115, 11678-11681 (2011).

4. Duan, L. et al. Thermally decomposable lithium nitride as an electron injection material for highly efficient and stable OLEDs. J. Phys. Chem. C 113, 13386-13390 (2009).

5. Baldwin, F. P., Blanchard, E. J. \& Koenig, P. E. Metal nitrides in organic reactions. I. Reactions of lithium nitride with acid chlorides. Preparation of N, N-diacylamides. J. Org. Chem. 30, 671-673 (1965).

6. Chen, P., Xiong, Z., Luo, J., Lin, J. \& Tan, K. L. Interaction of hydrogen with metal nitrides and imides. Nature 420, 302-304 (2002). 
7. Adams, P. F., Hubberstey \& P. Pulham, R. J. Review of the solubility of nonmetals in liquid lithium. J. Less-Common Met. 42, 1-11 (1975).

8. Kimura, H., Asano, M. \& Kubo, K. Vaporization of solid lithium nitride. J. Nucl. Mater. 91, 200-204 (1980).

9. Stach, E. A. et al. Watching GaN nanowires grow. Nano Lett. 3, 867-869 (2003).

10. Rodriguez, N. M., Chambers, A. \& Baker, R. T. K. Catalytic engineering of carbon nanostructures. Langmuir 11, 3862-3866 (1995).

11. Che, G., Lakshmi, B. B., Martin, C. R. \& Fisher, E. R. Chemical vapor deposition based synthesis of carbon nanotubes and nanofibres using a template method. Chem. Mater. 10, 260-267 (1998).

12. Fortuna, S. A. \& Li, X. Metal-catalysed semiconductor nanowires: a review on the control of growth directions. Semicond. Sci. Technol. 25, 024005 (2010).

13. Tang, D.-M., Liu, C. \& Chen, H.-M. Controlled synthesis of quasi-onedimensional boron nitride nanostructures. J. Mater. Res. 22, 2809-2816 (2007).

14. Kuykendall, T. R., Altoe, M. V. P., Ogletree, F. \& Aloni, S. Catalyst-directed crystallographic orientation control of GaN nanowire growth. Nano Lett. 14, 6767-6773 (2014).

15. Lugstein, A. et al. Pressure-induced orientation control of the growth of epitaxial silicon nanowires. Nano Lett. 8, 2310-2314 (2008).

16. Madras, P., Dailey, E. \& Drucker, J. Kinetically induced kinking of vaporliquid-solid grown epitaxial Si nanowires. Nano Lett. 9, 3826-3830 (2009).

17. Liu, H. et al. Reactant-governing growth direction of indium nitride nanowires. Nanotechnology 21, 245601 (2010).

18. Shen, Y. et al. Size-induced switching of nanowire growth direction: a new approach toward kinked nanostructures. Adv. Funct. Mater. 26, 3687-3695 (2016).

19. Chandrasekhar, H. R., Bhattacharya, G., Migoni, R. \& Bilz, H. Infrared and Raman spectra and lattice dynamics of the superionic conductor lithium nitride $\left(\mathrm{Li}_{3} \mathrm{~N}\right)$. Phys. Rev. B 17, 884-893 (1978).

20. Chandrasekhar, H. R., Bhattacharya, G., Migoni, R. \& Bilz, H. Phonon spectra and lattice dynamics of lithium nitride. Solid State Commun. 22, 681-684 (1977).

21. Nemanich, R. J. \& Solin, S. A. First- and second-order Raman scattering from finite-size crystals of graphite. Phys. Rev. B 20, 392-401 (1979).

22. Nemanich, R. J., Solin, S. A. \& Martin, R. M. Light scattering study of boron nitride microcrystals. Phys. Rev. B 23, 6348-6356 (1981).

23. Arenal, R. et al. Raman spectroscopy of single-wall boron nitride nanotubes. Nano Lett. 6, 1812-1816 (2006).

24. Kress, W., Grimm, H., Press, W. \& Lefebvre, J. Lattice vibrations in lithium nitride, $\mathrm{Li}_{3}$ N. Phys. Rev. B 22, 4620-4625 (1980).

25. Nesheva, D. Raman scattering from semiconductor nanoparticles and superlattices. J. Optoelectron. Adv. Mater. 7, 185-192 (2005).

26. Tenne, R. Inorganic nanotubes and fullerene-like materials. Chem. Eur. J. 8, 5296-5304 (2002).

27. Messer, R., Birli, H. \& Differt, K. NMR study of diffusion in $\mathrm{Li}_{3}$ N. J. Phys. C Solid State 14, 2731-2746 (1981).

28. Stoeva, Z., Gomez, R., Gregory, D. H., Hix, G. B. \& Titman, J. J. Evolution of structure, transport properties and magnetism in ternary lithium nitridometalates $\mathrm{Li}_{3-\mathrm{x}-\mathrm{y}} \mathrm{M}_{\mathrm{x}} \mathrm{N}, \mathrm{M}=\mathrm{Co}, \mathrm{Ni}, \mathrm{Cu}$. Dalton Trans. 3093-3097 (2004).

29. Jiang, C., Li, H. \& Wang, C. Recent progress in solid-state electrolytes for alkali-ion batteries. Sci. Bull. 62, 1473-1490 (2017).

30. Chan, C. K., Yang, T. J. \& Weller, J. M. Nanostructured garnet-type $\mathrm{Li}_{7} \mathrm{La}_{3} \mathrm{Zr}_{2} \mathrm{O}_{12}$ : synthesis, properties and opportunities as electrolytes for $\mathrm{Li}$-ion batteries. Electrochim. Acta 253, 268-280 (2017).

31. Rabenau, A. Lithium nitride and related materials case study of the use of modern solid state research techniques. Solid State Ionics 6, 277-293 (1982).

32. David, W. I. F. et al. A mechanism for non-stoichiometry in the lithium amide/lithium imide hydrogen storage reaction. J. Am. Chem. Soc. 129, 1594-1601 (2007).

33. Demir-Cakan, R., Tang, W. S., Darwiche \& Janot, A. R. Modification of the hydrogen storage properties of $\mathrm{Li}_{3} \mathrm{~N}$ by confinement into mesoporous carbons. Energy Environ. Sci. 4, 3625-3631 (2011).

34. Jiang, Z. P., Zhou, X., Sun, Q., Wang, Q. \& Jena, P. Geometry, electronic properties, and hydrogen adsorption properties of $\mathrm{Li}_{3} \mathrm{~N}$-based nanostructures. J. Phys. Chem. C 14, 19202-19205 (2010).

35. Jin, H. M., Luo, J. Z. \& Wu, P. Adsorption and dissociation of hydrogen on $\mathrm{Li}_{3} \mathrm{~N}$ surface: a first principles study. Appl. Phys. Lett. 90, 084101 (2007).

36. Wu, S., Neo, S. S., Dong, Z., Boey, F. \& Wu, P. Tunable ionic and electronic conduction of lithium nitride via phosphorus and arsenic substitution: a firstprinciples study. J. Phys. Chem. C 114, 16706-16709 (2010).

37. Zhao, Y., Tian, X., Xue, W. \& Gao, T. The structure, dynamical and thermodynamic properties of $\alpha-\mathrm{Li}_{3} \mathrm{~N}$ : a first-principles study. Solid State Commun. 149, 2130-2134 (2009).
38. Baumeier, B., Kruger, P., Pollmann, J. \& Vajenine, G. V. Electronic structure of alkali-metal fluorides, oxides, and nitrides: density-functional calculations including self-interaction corrections. Phys. Rev. B 78, 125111 (2008).

39. Dovesi, R., Pisani, C., Ricca, F., Roetti, C. \& Suanders, V. R. Hartree-Fock study of crystalline lithium nitride. Phys. Rev. B 30, 972-979 (1984).

40. Brendecke, H. \& Bludau, W. Photoluminescence properties of lithium nitride Phys. Rev. B 21, 805-815 (1980).

41. Sham, L. J. \& Schlüter, M. Density-functional theory of the band gap. Phys. Rev. B 32, 3883-3889 (1985).

42. Sham, L. J. \& Schlüter, M. Density-functional theory of the energy gap. Phys. Rev. Lett. 51, 1888-1891 (1983).

43. Partoens, B. \& Peeters, F. M. From graphene to graphite: electronic structure around the K point. Phys. Rev. B 74, 075404 (2006).

44. Song, L. et al. Large scale growth and characterization of atomic hexagonal boron nitride layers. Nano Lett. 10, 3209-3215 (2010).

45. Blase, X. et al. Quasiparticle band structure of bulk hexagonal boron nitride and related systems. Phys. Rev. B 51, 6868-6875 (1995).

46. Hoffman, D. M., Doll, G. L. \& Eklund, P. C. Optical properties of pyrolytic boron nitride in the energy range $0.05-10 \mathrm{eV}$. Phys. Rev. B 30, 6051-6056 (1984).

47. Sun, Y. et al. Stabilised $\mathrm{Li}_{3} \mathrm{~N}$ for efficient battery cathode prelithiation. Energy Storage Mater. 6, 119-124 (2017).

48. Bian, $Z$. et al. Dual roles of $\mathrm{Li}_{3} \mathrm{~N}$ as an electrode additive for $\mathrm{Li}$-excess layered cathode materials: a Li-ion sacrificial salt and electrode-stabilizing agent. Chem. Eur. J. 24, 13815-13820 (2018).

49. Park, K. \& Goodenough, J. B. Dendrite-suppressed lithium plating from a liquid electrolyte via wetting of $\mathrm{Li}_{3} \mathrm{~N}$. Adv. Energy Mater. 7, 1700732 (2017).

50. Baloch, M. et al. Variations on $\mathrm{Li}_{3} \mathrm{~N}$ protective coating using ex-situ and insitu techniques for $\mathrm{Li}^{\circ}$ in sulphur batteries. Energy Storage Mater. 9, 141-149 (2017).

51. Barker, M. G., Begley, M. J., Edwards, P. P., Gregory, D. H. \& Smith, S. E. Synthesis and crystal structures of the new ternary nitrides $\mathrm{Sr}_{3} \mathrm{CrN}_{3}$ and $\mathrm{Ba}_{3} \mathrm{CrN}_{3}$. J. Chem. Soc. Dalton Trans. 1-5 (1996).

52. Holland, T. J. B. \& Redfern, S. A. T. Unit cell refinement from powder diffraction data: the use of regression diagnostics. Mineral. Mag. 61, 65-77 (1997).

53. Blackman, J. M., Patrick, J. W. \& Snape, C. P. An accurate volumetric differential pressure method for the determination of hydrogen storage capacity at high pressures in carbon materials. Carbon 44, 918-927 (2006).

54. Perdew, J., Burke, K. \& Ernzerhof, M. Generalized gradient approximation made simple. Phys. Rev. Lett. 77, 3865-3868 (1996).

55. Soler, J. M. et al. The SIESTA method for ab initio order-N materials simulation. J. Phys. Condens. Matter 14, 2745 (2002).

56. Troullier, N. \& Martins, J. L. Efficient pseudopotentials for plane-wave calculations. Phys. Rev. B 43, 1993 (1991).

57. Monkhorst, H. J. \& Pack, J. D. Special points for Brillouin-zone integrations. Phys. Rev. B 13, 5188-5192 (1976).

\section{Acknowledgements}

D.H.G. acknowledges the EPSRC for financial support under grants GR/S26965 and EP/ E040071, the University of Nottingham for studentships to A.G.G. and H.K.E., the University of Glasgow for a studentship to C.W.D. and ScotCHEM for a studentship to N.T.-R. E.B. acknowledges a New Directions for EPSRC Research Leaders Award (EP/ G005060), the European Research Council under the European Union's Seventh Framework Programme (FP7)/ERC grant agreement No. 307755-FIN and a Royal Society Wolfson Fellowship for financial support. M.B. and E.B. acknowledge the use of Athena at HPC Midlands+, which was funded by the EPSRC on grant EP/P020232/1 as part of the HPC Midlands+ consortium.

\section{Author contributions}

N.T.-R., A.G.G., C.M.J. and C.W.D. developed the synthesis methods and characterised materials by X-ray diffraction, spectroscopy and electron microscopy; H.K.E., P.D.B. and I.M. performed transmission electron microscopy and electron diffraction experiments and analysed and interpreted these data; J.M.B., C.P.S., C.M.J. and N.T.-R. performed hydrogen uptake experiments, analysed and interpreted these data; M.B. and E.B. performed computational calculations, analysed, interpreted the data and prepared these for publication; J.J.T. designed the solid-state NMR experiments and collected and interpreted the NMR data; D.H.G. initiated and supervised the project and analysed and interpreted the data. N.T.-R., J.J.T., E.B. and D.H.G. wrote the manuscript. All authors discussed the results and commented on the paper.

\section{Competing interests}

The authors declare no competing interests. 


\section{Additional information}

Supplementary information is available for this paper at https://doi.org/10.1038/s41467020-17951-6.

Correspondence and requests for materials should be addressed to D.H.G.

Peer review information Nature Communications thanks Albert Davydov, Moneesh Upmanyu and the other anonymous reviewer(s) for their contribution to the peer review of this work.

Reprints and permission information is available at http://www.nature.com/reprints

Publisher's note Springer Nature remains neutral with regard to jurisdictional claims in published maps and institutional affiliations. (c) (i) Open Access This article is licensed under a Creative Commons Attribution 4.0 International License, which permits use, sharing, adaptation, distribution and reproduction in any medium or format, as long as you give appropriate credit to the original author(s) and the source, provide a link to the Creative Commons license, and indicate if changes were made. The images or other third party material in this article are included in the article's Creative Commons license, unless indicated otherwise in a credit line to the material. If material is not included in the article's Creative Commons license and your intended use is not permitted by statutory regulation or exceeds the permitted use, you will need to obtain permission directly from the copyright holder. To view a copy of this license, visit http://creativecommons.org/ licenses/by/4.0/.

(C) The Author(s) 2020 